\title{
Developing a dynamic growth model for teak plantations in India
}

\author{
Vindhya Prasad Tewari ${ }^{*}$, Juan Gabriel Álvarez-gonzález ${ }^{2}$ and Oscar García ${ }^{3}$
}

\begin{abstract}
Background: Tectona grandis (teak) is one of the most important tropical timber species occurring naturally in India. Appropriate growth models, based on advanced modeling techniques, are not available but are necessary for the successful management of teak stands in the country. Long-term forest planning requires mathematical models, and the principles of Dynamical System Theory provide a solid foundation for these.

Methods: The state-space approach makes it possible to accommodate disturbances and avarying environment. In this paper, an attempt has been made to develop a dynamic growth model based on the limited data, consisting of three annual measurements, collected from 22 teak sample plots in Karnataka, Southern India.

Results: A biologically consistent whole-stand growth model has been presented which uses the state-space approach for modelling rates of change of three state-variables viz., dominant height, stems per hectare and stand basal area. Moreover, the model includes a stand volume equation as an output function to estimate this variable at any point in time. Transition functions were fitted separately and simultaneously. Moreover, a continuous autoregressive error structure is also included in the modelling process. For fitting volume equation, generalized method of moments was used to get efficient parameter estimates under heteroscedastic conditions.
\end{abstract}

Conclusions: A simple model containing few free parameters performed well and is particularly well suited to situations where available data is scarce.

Keywords: Mortality; Basal area; Canopy closure; Relative occupancy; State-space approach; Tectona grandis

\section{Background}

\section{About the species and its distribution}

Teak (Tectona grandis L. f.) is one of the most important tropical timber species and is suitable for multiple enduses. The potential for growing and managing teak in different ecological zones and under different situations is being increasingly recognized, leading to intensive domestication and cultivation of the species in countries/regions beyond its natural habitat (Perez and Kanninen, 2003).

Teak occurs naturally in parts of India, Myanmar, Laos and Thailand. It has been naturalized in Java, where it was introduced about 400-600 years ago (Kadambi, 1972; White, 1991). Early introductions of teak outside Asia were made in Nigeria in 1902, with the first plantations being of Indian origin and subsequently of Burmese origin (Horne, 1966). The first pure teak plantation in Tropical America

\footnotetext{
* Correspondence: vptewari@yahoo.com

${ }^{1}$ Forest Biometry Division, Institute of Wood Science and Technology, Bangalore, India

Full list of author information is available at the end of the article
}

was established in Trinidad in 1913. Teak planting in Honduras, Panama, and Costa Rica started between 1927 and 1929 (Ball et al., 2000).

Teak is the world's most cultivated high-grade tropical heartwood, covering approximately 6.0 million hectares worldwide (Bhat and Hwan Ok Ma, 2004). Of this, about 94\% are in Tropical Asia, with India (44\%) and Indonesia (31\%) contributing the bulk of the resource. Other countries like Thailand, Myanmar, Bangladesh and Sri Lanka contribute significantly with $17 \%$ in total. About $4.5 \%$ of the teak plantations are in Tropical Africa and the rest are in Tropical America, mostly in Costa Rica and Trinidad and Tobago (Pandey, 1998).

The most important teak forests in India are in Madhya Pradesh, Maharashtra, Karnataka, Tamil Nadu and Kerala, and also in Uttar Pradesh, Gujarat, Orissa and Rajasthan (Troup, 1921). Plantations have also been made in Haryana, West Bengal, Assam, Meghalaya and Dadra and Nagar 
Haveli (Chakrbarti and Gaharwar, 1995). However, many plantations are in a state of neglect.

\section{Management of teak forests in Karnataka}

The teak forests in India are managed based on the approved working plans (generally prescribed for ten years). The rotation period prescribed for teak in Karnataka is usually 120 years. The following mechanical (systematic; row thinning) and silvicultural (selective) thinning regimes are prescribed by the Karnataka State Forest Department.

First mechanical thinning in the 6th year

(retaining about 1700-1800 tree ha ${ }^{-1}$ ).

Second mechanical thinning in the 12th year (retaining about 1000-1100 trees $\mathrm{ha}^{-1}$ ).

First silvicultural thinning in the 18th year

(retaining about 700-800 trees $\mathrm{ha}^{-1}$ ).

Second silvicultural thinning in the 30th year (retaining about 500-550 trees $\mathrm{ha}^{-1}$ ).

Third silvicultural thinning in the 38th year (retaining about 300-350 trees $\mathrm{ha}^{-1}$ ).

An elite thinning at the end of 80th year

(retaining about 150 trees $\mathrm{ha}^{-1}$ ).

However, this working plan prescription is not strictly followed in most cases due to various reasons. In some areas, trees are damaged bythe elephants and these damaged trees may be extracted every year.

\section{Growth models}

Reliable growth models are essential for effective longterm planning and decision making. This is especially important in intensively managed forest plantations, where it is necessary to evaluate alternative planting densities, thinning regimes, and rotation lengths (Garcia et al., 2011). Empirical models describe and generalize observed stand behaviour. They can be accurate and highly successful in fulfilling many of the forest manager's needs (Burkhart, 2008). However, they require extensive longterm experimental data, and extrapolation to unobserved situations can be uncertain. A theory-based model would describe hypothesized behaviour by reasoning from first principles. Theory-influenced semi-empirical models attempt to be compatible with observations, while at the same time use theoretical knowledge and hypotheses to improve performance under conditions for which data are scarce (Mohren and Burkhart, 1994).

In this paper, we present a biologically consistent whole-stand growth model for teak using data from the Karnataka State of Peninsular India. The main motivation was to produce a simple and robust base-line model for teak stands. The model uses the state-space approach for modelling rates of change of three state-variables: dominant height, number of trees per hectare and stand basal area. Moreover, the model includes a stand volume equation as an output function to estimate this variable at any point in time.

This research presents some new methodological contributions for developing growth models based on the state-space approach and differentiate from the past work using similar approach (e.g. García et al., 2011) in the sense that García et al. (2011) fitted each transition function separately, however, in this study the transition functions for mortality and basal area were fitted simultaneously using the full information maximum likelihood. Also, autoregressive procedure has been used in the present study to remove the problem of autocorrelation inherent in the dataset from repeated measurements. Further, volume equation was fitted using generalized method of moments to obtain efficient parameter estimates under heteroscedastic conditions even without estimating the heteroscedastic error variance.

\section{Methods \\ Data}

The data used in this study were collected on 27 pure and even-aged Teak research plots of different ages (11 to 38 years) and densities ( 498 to 2061 trees $\mathrm{ha}^{-1}$ ) established in 2010 in stands representing five forest divisions in Karnataka. The annual rainfall in these areas varies from $1600 \mathrm{~mm}$ to $4500 \mathrm{~mm}$. The mean annual minimum and maximum temperatures vary from $11^{\circ} \mathrm{C}$ to $38^{\circ} \mathrm{C}$. The plots are located throughout the teak growing areas in the state and were selected to represent the existing range of ages, stand densities and sites. The plots are rectangular and their size ranged from 220 to $436 \mathrm{~m}^{2}$, depending on stand density, in order to achieve a minimum of 30 trees per plot. The diameter at breast height ( $\mathrm{dbh}, 1.37 \mathrm{~m}$ above the ground) was measured to the nearest $0.1 \mathrm{~cm}$ with digital callipers in all trees in the plots. Total height was measured to the nearest $0.1 \mathrm{~m}$ with a digital hypsometer. Age was calculated from the year of planting. The plots were re-measured annually during 2010-2013 and a total of three annual measurements were available for each plot.

The plot data includes: stand age ( $t$, years), density $\left(N\right.$, trees $\left.\mathrm{ha}^{-1}\right)$, quadratic mean diameter $(D, \mathrm{~cm})$,

Table 1 Summarized data of the sample plots used for model development

\begin{tabular}{lcccc}
\hline Stand variable & Mean & Minimum & Maximum & SD \\
\hline$t$ (years) & 29.20 & 11.00 & 38.00 & 5.52 \\
\hline$N\left(\right.$ trees ha $\left.{ }^{-1}\right)$ & 980.98 & 498.00 & 2061.00 & 364.16 \\
\hline$D(\mathrm{~cm})$ & 17.24 & 5.50 & 36.00 & 5.95 \\
\hline $\bar{h}(\mathrm{~m})$ & 15.61 & 6.78 & 22.36 & 3.26 \\
\hline$H(\mathrm{~m})$ & 19.28 & 10.71 & 28.43 & 3.73 \\
\hline$B\left(\mathrm{~m}^{2} \mathrm{ha}^{-1}\right)$ & 23.12 & 6.47 & 37.49 & 7.10 \\
\hline$V\left(\mathrm{~m}^{3} \mathrm{ha}^{-1}\right)$ & 195.04 & 21.47 & 412.09 & 82.59 \\
\hline
\end{tabular}


average height $(\bar{h}, m)$, dominant height $(H, \mathrm{~m})$, defined as the mean height of the 100 thickest trees per hectare, basal area $\left(B, \mathrm{~m}^{2} \mathrm{ha}^{-1}\right)$ and total stand volume $\left(V, \mathrm{~m}^{3}\right)$. Total stand volume was calculated from a compatible tree volume equation (Tewariet al., 2013). The summary statistics of these stand variables are shown in Table 1. Although, the mechanical (systematic) and silvicultural (selective) thinnings are prescribed in the forest management working plans, however, thinning was carried out only in one stand. Moreover, an exhaustive examination of the data was carried out to reject sample plots on which illegal logging had been detected to make sure that the reduction in number of trees observed were due to natural mortality.

\section{Model structure}

Out of the 27 plots, 5 plots, on which illegal logging had been detected, were excluded from the analysis. The dynamic growth model developed from these data is based on the state-space approach and it is similar to those of García (2011), García et al. (2011) and García (2013). In this model it is assumed that the behaviour of any stand of teak evolving in time can be approximated by describing its current state with four state variables: dominant height $(H)$, number of trees per hectare $(N)$, basal area $(B)$, and a measure of site occupancy $(\Omega)$, using transition functions to estimate the change of states as a function of the current state of the variables.

The transition functions are used to predict the growth by updating the state variables, ensuring two natural properties (García, 1994): (i) consistency, meaning no change for zero elapsed time; (ii) pathinvariance, where the result of projecting the state first from $t_{0}$ to $t_{1}$, and then from $t_{1}$ to $t_{2}$, must be the same as that of the one-step projection from $t_{0}$ to $t_{2}$. Transition functions generated by integration of differential equations (or summation of difference equations when using discrete time) satisfy these conditions and allow computing the future state trajectory. These properties can also be achieved by using techniques for dynamic equation derivation known in forestry as the Algebraic Difference Approach (ADA; Bailey and Clutter, 1974) or its generalization (GADA; Cieszewski and Bailey, 2000).

\section{Transition function for dominant height}

The two-site-specific parameter equation, derived from the Korf base model and proposed by Tewari et al. (2014), was used as transition function for dominant height. The GADA model allows simultaneous concurrent polymorphism and multiple asymptotes, two characteristics of site equations that are sometimes desirable
(Cieszewski, 2002). The mathematical expression of this model is

$$
\begin{aligned}
& H_{2}=\exp \left(X_{0}\right) \exp \left(-\left(13.6964+22.3517 / X_{0}\right) t_{2}{ }^{-1.2229}\right) \text { with } \\
& X_{0}=\frac{1}{2} t_{1}{ }^{-1.2229}\left(\begin{array}{l}
13.6964+t_{1}{ }^{1.2229} \ln \left(H_{1}\right)+ \\
+\sqrt{89.4068 t_{1}{ }^{1.2229}+\left(13.6964+t_{1}{ }^{1.2229} \ln \left(H_{1}\right)\right)^{2}}
\end{array}\right)
\end{aligned}
$$

where, $H_{1}$ and $t_{1}$ represent the predictor height (meters) and age (years), and $H_{2}$ is the predicted height at age $t_{2}$.

\section{Transition function for mortality}

Natural mortality or survival is extremely variable and, particularly difficult to predict. The mortality transition function is based on assuming that the rate of change of $N$ relative to dominant height increment depends on the current values of $H$ and $N$ :

$$
\frac{d N}{d H}=-a_{1} H^{a_{2}} N^{a_{3}}
$$

where, $N$ is number of trees $\mathrm{ha}^{-1}, H$ is the dominant height and $a_{\mathrm{i}}$ are parameters to be estimated.

Grouping the terms of equation (2) and integrating both sides gives the following invariant:

$$
\frac{d N}{N^{a_{3}}}=-a_{1} H^{a_{2}} d H \Rightarrow N^{1-a_{3}}-\frac{a_{1}\left(a_{3}-1\right)}{a_{2}+1} H^{a_{2}+1}=\mathrm{constant}
$$

Equating the invariant for times 1 and 2 gives the following transition function for number of trees $\mathrm{ha}^{-1}$ :

$$
N_{2}=\left[N_{1}^{1-a_{3}}+a_{1} \frac{a_{3}-1}{a_{2}+1}\left(H_{2}^{a_{2}+1}-H_{1}^{a_{2}+1}\right)\right]^{1 /\left(1-a_{3}\right)}
$$

This predicts $N_{2}$ at a height $H_{2}$ given any initial values $\left(H_{1} ; N_{1}\right)$. Equation (4) was fitted using two different approaches. In the first case, no parameter restrictions were assumed while in the second case, parameter restrictions were obtained by assuming limiting values for the slope of the self-thinning lines based on the average square spacing $S=100 / \sqrt{N}$ (Garcia, 2009). The rate of change of average square spacing relative to dominant height increment depends on the initial values of the same variables:

$$
\frac{d S}{d H}=\beta^{\gamma} \frac{H^{\gamma-1}}{S^{\alpha-1}}
$$

Integrating equation (5) and taking logarithms, the following invariant is obtained: 


$$
\begin{aligned}
& S^{\alpha}=\frac{\alpha}{\gamma}(\beta H)^{\gamma} \Rightarrow \alpha \log (100)-\frac{\alpha}{2} \log (N)=\log (\alpha / \gamma) \\
& +\gamma \log (\beta)+\gamma \log (H) \Rightarrow \\
& \Rightarrow \log (N)=-2 \frac{\gamma}{\alpha} \log (H)+\text { constant }
\end{aligned}
$$

Any limiting value assumed for $2 \gamma / \alpha$ in equation (6) represents the slope of the self-thinning line assumed for the species. Comparing with equation (3), the following relationship is obtained:

$$
-2 \frac{\gamma}{\alpha}=\frac{a_{2}+1}{1-a_{3}}
$$

This relationship could be useful to estimate the parameters of the mortality transition function when the available data is limited, to assure a biologically consistent behaviour (García, 2009). Values of 2 and 3 were assumed for the $-2 \gamma / \alpha$ ratio, i.e. for the slope of the selfthinning line.

\section{Transition function for basal area}

Instead of predicting basal area $(B)$ directly, we choose to model growth of the product $W=B H$. The rate of change of $W$ can be expressed as the difference between two components: the gross increment and the mortality. In pure and even-aged stands (such as those considered in this article), the gross increment can be written as $b_{1} \Omega H N^{b_{2}}$, where $\Omega$ is a relative occupancy factor that reduces growth in young or recently thinned stands that do not still fully occupy the site. The mortality as $-k \frac{W}{N}$ $\frac{d N}{d H}=-k W \frac{d \log N}{d H}$, where $k$ represent the mean size of dying trees relative to the mean size of the survivors, considered as constant. Therefore, the general W growth model is:

$$
\frac{d W}{d H}=b_{1} \Omega H N^{b_{2}}+k W \frac{d \log N}{d H}
$$

A simple closed-form solution of the differential equation (8) can be achieved in the special case where $b_{2}$ is equal to $k$ :

$$
\frac{d W}{d H}=b_{1} \Omega H N^{k}+k W \frac{d \log N}{d H}
$$

Intuitively, $\Omega$ represents resource (e.g. light, nutrient, moisture) interception. In the beginning, occupancy is low in young stands, and gradually increases approaching 1 when canopy closes. We assume that the rate of closure initially depends on $H$ in the same way as the gross increment, and decreases to zero as full closure is approached.

$$
\frac{d \Omega}{d H}=c_{1} H(1-\Omega)
$$

Integration gives the invariant:

$$
(1-\Omega) \exp \left(c_{1} H^{2} / 2\right)=\text { constant }
$$

With this occupancy model, integration of equation (9) gives the transition equation for basal area:

$$
B_{2}=N_{2}^{k}\left(B_{1} H_{1} N_{1}^{-k}+b_{1}\left[\left(H_{2}^{2}-H_{1}^{2}\right) / 2-\left(\Omega_{2}-\Omega_{1}\right) / c_{1}\right]\right) / H_{2}
$$

with

$$
\Omega_{2}=1-\exp \left[-c_{1}\left(H_{2}^{2}-H_{1}^{2}\right) / 2\right]\left(1-\Omega_{1}\right)
$$

In order to understand the methodology and the derivation of the transition equation for basal area, the integration of the differential equation (9) has been provided as Appendix.

\section{Total stand volume equation}

Volumes per hectare can be estimated given the state variables using an output function. Two different total stand volume equations were fitted using as independent variables dominant height and basal area.

$$
\begin{aligned}
& V=e_{1}+e_{2} H B \\
& V=e_{1} H^{e_{2}} B^{e_{3}}
\end{aligned}
$$

These models have been widely used to estimate total stand volume (see, for instance, Husch et al., 2003; van Laar and Akça, 2007; Weiskittel et al., 2011).

The models were fitted using the generalized method of moments (GMM) in the MODEL procedure of SAS/ ETS $^{\circ}$ (SAS Institute Inc., 2008). This method produces efficient parameter estimates under heteroscedastic conditions, without estimating the heteroscedastic error variance (Greene, 2012). The main drawback of this method is that error estimates for the predictions can not be generated without specifying the error structure (Parresol, 2001).

\section{Parameter estimation and model selection}

The model was fitted based on projections over pairs of consecutive measurements. Since the transition function for dominant height was fitted previously, the observed dominant heights in the database were substituted by the predicted values of this model in order to include the error of estimations in the whole-stand growth model. It was considered convenient to initialize the state variables at breast height, where $H=1.37$ and $B=0$ are known. The number $N_{\mathrm{b}}$ of trees per hectare at this time was estimated by applying an $82.5 \%$ survival (since the survival rate observed after one year of planting in these stands was $80-85 \%$ ) to the density from the 
spacing adopted at the time of planting which was $2 \times$ $2 \mathrm{~m}$ except for one plot in which it was $1.5 \times 1.5 \mathrm{~m}$. Following Garcia (2011), the occupancy was initialized at breast height as:

$$
\Omega_{b}=1-\left(1-\min \left\{N_{b} / c_{2}, 1\right\}\right)^{c_{3}}
$$

where, $c_{\mathrm{i}}$ are parameters to be estimated; $c_{2}$ represents a breast-height density at which the stand would be fully closed.

García et al. (2011) fitted each transition function separately. Here the transition functions for mortality and basal area were fitted simultaneously using the full information maximum likelihood (FIML) in order to obtain estimates that are consistent and efficient and contribute in increased precision of model predictions. Since the convergence with this approach is very sensitive to the starting values of the parameters, both transition functions were first fitted separately to get the best set of initial values.

Individual tree forest growth and yield models usually employ a set of equations to describe stand development over time. It is not unusual in the forestry literature to treat the same variable as dependent in one equation and independent in another. When a variable is used as both an endogenous (dependent) variable on the lefthand side of one equation and on the right-hand side of another equation, this renders the system of equation simultaneous (Goldberger, 1964). In the present study, mortality is used as dependent variable in equation (4) and as an independent variable in equation (12), making the system of equations simultaneous. Simultaneous regression techniques lead to more efficient estimators. A gain in efficiency increases the precision of the resulting model predictions. The gain in efficiency is higher when the errors among different equations are highly correlated (Judge et al., 1988).

The error was modelled using a continuous autoregressive error structure $(\operatorname{CAR}(x))$, which accounted for the time between measurements. Age at breast height was estimated using an iterative procedure based on the transition function of dominant height previously described. Different ages at breast height were used to estimate the dominant heights at the age of plots measurements and the age which minimized the sum of squares of the differences between observed and predicted dominant heights was selected as age at breast height. Those ages were only used to obtain correct consistent estimates of the parameters and their standard errors.

Estimation of the parameters was carried out with the MODEL procedure of SAS/ETS ${ }^{\triangleright}$ (SAS Institute Inc., 2008). The $\operatorname{CAR}(x)$ error structure was programmed in this procedure which allows for dynamic updating of the residuals.
The comparison of the estimates for the different models was based on numerical and graphical analyses of the residuals. Two statistical criteria were examined: adjusted model efficiency $\left(M E_{a d j}\right)$ and root mean square error $(R M S E)$. The expressions of these statistics are summarized as follows:

$$
\begin{aligned}
M E_{\text {adj }}= & \frac{\sum_{i=1}^{n}\left(y_{i}-\hat{y}_{i}\right)^{2} /(n-p)}{\sum_{i=1}^{n}\left(y_{i}-\bar{y}\right)^{2} /(n-1)} \\
R M S E & =\sqrt{\frac{\sum_{i=1}^{n}\left(Y_{i}-\hat{Y}_{i}\right)^{2}}{n-p}}
\end{aligned}
$$

where, $y_{i}, \hat{y}_{i}$ and $\bar{y}$ are the observed, estimated and mean values of the dependent variable, $n$ is the total number of observations used to fit the model, and $p$ is the number of model parameters.

In addition to the validation of individual components of the dynamic growth model, overall validation of the whole model was carried out. All possible combinations of inventories were used and the observed $H, N$ and $B$ values from the first inventory were used to estimate total stand volume at the age of the last inventory, including all the components of the whole stand model. In order to evaluate whether the model performs acceptably well when used for estimating total stand volume, a critical error, expressed as a percentage of the observed mean, was computed (Reynolds, 1984):

$$
E_{\text {crit. }}=\frac{\sqrt{\tau^{2} \sum_{i=1}^{n}\left(y_{i}-\hat{y}_{i}\right)^{2} / \chi_{c r i t .}^{2}}}{\bar{y}}
$$

where, $n$ is the total number of observations in the data set, $y_{\mathrm{i}}, \hat{y}_{i}$ and $\bar{y}$ are the observed, predicted and mean values of total stand volume, and $\tau$ is a standard normal deviate at the specified probability level $(\tau=1.96$ for $\alpha=$ 0.05). $X_{n}^{2}$ is obtained for $\alpha=0.05$ with $n$ degrees of freedom. In addition to using this statistic, the plot of observed against predicted values of the total stand volume was also inspected.

\section{Results and discussion}

At first, the transition functions for mortality and basal area were fitted separately using nonlinear least squares and without assuming autocorrelation. However, a slight trend in residuals as a function of lag1 residuals within the same sample plot was apparent in all the models. Then, all the models were refitted using a first-order continuous-time autoregressive error structure. After 


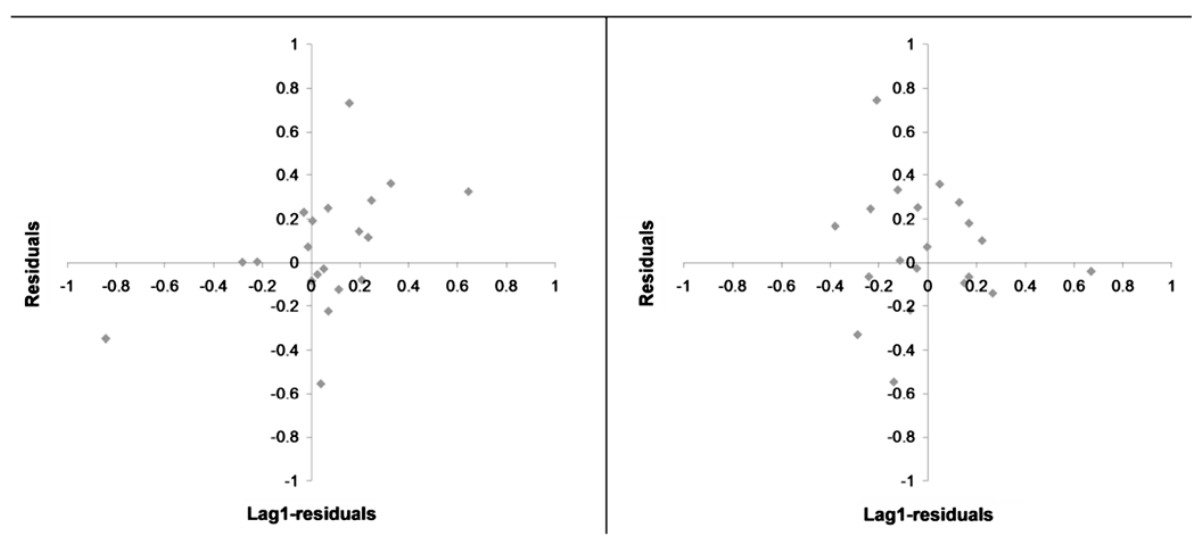

Figure 1 Basal area residuals versus basal area Lag1-Residuals for equation (12) fitted without taking into account autocorrelation (left) and fitted using a first-order continuous time autoregressive error structure (right).

applying this correction, the error trends in residuals disappeared (Figure 1).

\section{Separate fitting}

Three transition functions for mortality were analyzed and the results are presented in Table 2. The first one is based on equation (4) without assuming any restrictions for the parameters and the other two are based on assuming values of 2 and 3 for the slope of the selfthinning line according to equation (7). The three models explained more than $98 \%$ of the total variance, calculated without considering the initialized point at breast height, and the model with a value of 2 for self-thinning line resulted in the best values of the goodness-of-fit statistics.

Natural tree mortality is a complex process that is neither constant in time nor in space, so it is difficult to predict or explain the factors that control it (Van Laar and Açka, 2007). Data from permanent sample plots frequently show that a relatively large part of the plots have no occurrences of mortality even over periods of several years and sometimes an important reduction in trees per hectare occurs in short periods of time (e.g. Monserud and Sterba, 1999; Eid and Tuhus, 2001). Therefore, for a correct mortality modeling, an adequate combination of short and long intervals between measurements is essential. The time interval between consecutive measurements of the database used in this study is one year and the models fitted show a good performance for these short periods, within the age interval covered in the sample plots. However, the behavior of the models for long periods projected from the breast age showed high levels of mortality (Figure 2).

The results of the fitting of the basal area transition function are shown in Table 3. It was not possible to obtain convergence or reasonable estimates with all the parameters. Therefore, as in Garcia et al. (2011), we fixed $c_{3}$ in equation (16) with the value 2.4 and $c_{2}$ in the same equation with the value 10000 , implying full canopy closure at breast height with 10000 trees ha $^{-1}$. It had been shown that these values are not critical (García, 2011; García et al., 2011).

In a first step, the model (Equation 12) was fitted without assuming any other restriction for the remaining three parameters $\left(k, b_{1}\right.$ and $\left.c_{1}\right)$, however, unrealistically small values for parameters $k$ and $c_{1}(0.2121$ and 0.0369 , respectively) were obtained. In a second step, the transition function was fitted assuming a value of 0.4 for parameter $k$ (García, 2011), however, the graphical representation indicated that the estimated value of $c_{1}$ was unrealistic again (0.0239). Finally, the model was fitted assuming $k=0.4$ and two different values for $c_{1}, 0.05$ and 0.01 . Figure 3 shows occupancy curves for various values of $c_{1}$ generated with equation (13), starting from 2062 trees per hectare at

Table 2 Parameter estimates for the mortality transition function (Equation 4) and goodness-of-fit statistics calculated without considering the initialized point at breast height

\begin{tabular}{|c|c|c|c|c|c|}
\hline \multirow[b]{2}{*}{ Model } & \multicolumn{3}{|c|}{ Parameters } & \multicolumn{2}{|c|}{ Goodness-of-fit statistics } \\
\hline & $a_{1}$ & $a_{2}$ & $a_{3}$ & RMSE & Adj. model efficiency \\
\hline 3 parameters & $8.43 \times 10^{-10}$ & 1.8792 & 2.8462 & 43.1573 & 0.9845 \\
\hline$\frac{a_{2}+1}{1-a_{2}}=3^{*}$ & $1.94 \times 10^{-7}$ & 2.0681 & 2.0227 & 39.7096 & 0.9869 \\
\hline$\frac{a_{2}+1}{1-a_{3}}=2^{*}$ & $1.66 \times 10^{-8}$ & 1.8703 & 2.4352 & 38.2869 & 0.9881 \\
\hline
\end{tabular}

*indicated the parameter value was fixed in the model, therefore, it was not estimated. 


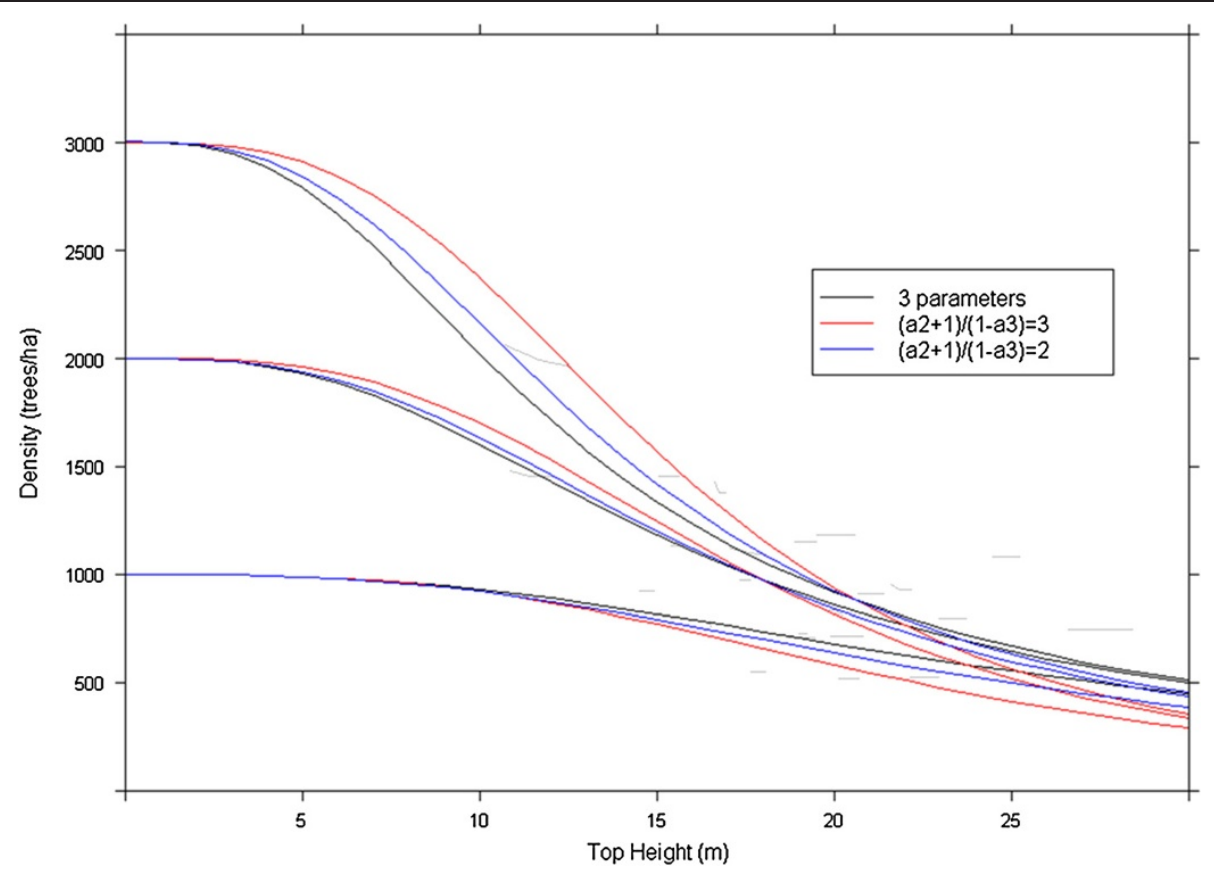

Figure 2 Data and mortality models. Projections starting from $H=1.37 \mathrm{~m}$ and $\mathrm{N}_{1}$ equal to 1000, 2000 and 3000 trees per hectare.

breast height. Also shown is the relative closure, $R$, which can be seen as representing the amount of foliage and roots relative to that of a closed stand. Closure and occupancy are related by $\Omega=1-(1-R)^{c_{3}}$. Both selected values for $c_{1}, 0.05$ and 0.1 seem reasonable, implying nearly closed canopies somewhere between 5 and $10 \mathrm{~m}$ top height. Or seen in another way; an equilibrium canopy depth of 5 to $10 \mathrm{~m}$. The best goodness-of-fit statistics was obtained constraining $c_{1}$ to 0.05 and this value was used in the simultaneous fitting. The model explained more than $99 \%$ of the total variance, calculated without considering the initialized point at breast height.

\section{Simultaneous fitting}

The results of the simultaneous fitting of both transition functions (Equation 4 for mortality and Equation 12 for

Table 3 Parameter estimates for the basal area transition function (Equation 12) and goodness-of-fit-statistics calculated without considering the initialized point at breast height

\begin{tabular}{cccccc}
\hline \multicolumn{3}{c}{ Parameters } & & \multicolumn{2}{c}{ Goodness-of-fit statistics } \\
\cline { 1 - 2 } \cline { 5 - 6 } $\boldsymbol{k}$ & $\boldsymbol{c}_{\mathbf{1}}$ & $\boldsymbol{b}_{\mathbf{1}}$ & & RMSE & Adjusted model efficiency \\
\hline 0.2122 & 0.0369 & 0.6270 & & 0.5638 & 0.9939 \\
\hline $0.4^{*}$ & 0.0239 & 0.1844 & 0.6998 & 0.9906 \\
\hline $0.4^{*}$ & $0.1^{*}$ & 0.1648 & 0.5636 & 0.9939 \\
\hline $0.4^{*}$ & $0.05^{*}$ & 0.1706 & 0.6597 & 0.9917 \\
\hline
\end{tabular}

*indicated the parameter value was fixed in the model, therefore, it was not estimated. basal area) are shown in Table 4. Finally, two total stand volume equations were fitted separately. All the parameters were significant except for the intercept of equation (14). Both models performed equally good, although the best statistical criteria were obtained with equation (15) which explained more than $97 \%$ of the total volume variability with a root mean square error of $13.34 \mathrm{~m}^{3} \mathrm{ha}^{-1}$. The final expression of the dynamic model is as follows:

$$
\begin{aligned}
& N_{2}=\left[N_{1}^{-1.4352}+0.835 \cdot 10^{-9}\left(H_{2}^{2.8703}-H_{1}^{2.8703}\right)\right]^{-0.6968} \\
& B_{2}=N_{2}^{0.4}\left(B_{1} H_{1} N_{1}^{-0.4}+0.1663\left[\left(H_{2}^{2}-H_{1}^{2}\right) / 2\right.\right. \\
& \left.\left.\quad \quad-\left(\Omega_{2}-\Omega_{1}\right) / 0.1\right]\right) / H_{2} \\
& \Omega_{2}=1-\exp \left[-0.1\left(H_{2}^{2}-H_{1}^{2}\right) / 2\right]\left(1-\Omega_{1}\right) \\
& \Omega_{b}=1-\left(1-\min \left\{N_{b} / 10000,1\right\}\right)^{2.4} \\
& V=0.4628 H^{0.8063} B^{1.1547}
\end{aligned}
$$

\section{Evaluation}

Critical errors of $1.11 \%, 3.45 \%$ and $8.9 \%$ were obtained for total stand volume at time intervals of 1,2 and 3 years. The critical errors obtained with the proposed model are lower compared to that obtained for projecting total stand volume in Scots pine (15.3\%) in Galicia (Diéguez-Aranda et al., 2006) and the ones obtained for the same stand variable in radiata pine $(10.9 \%, 11.9 \%$ and $17.3 \%$ ) in Galicia, considering time intervals of 3, 6 


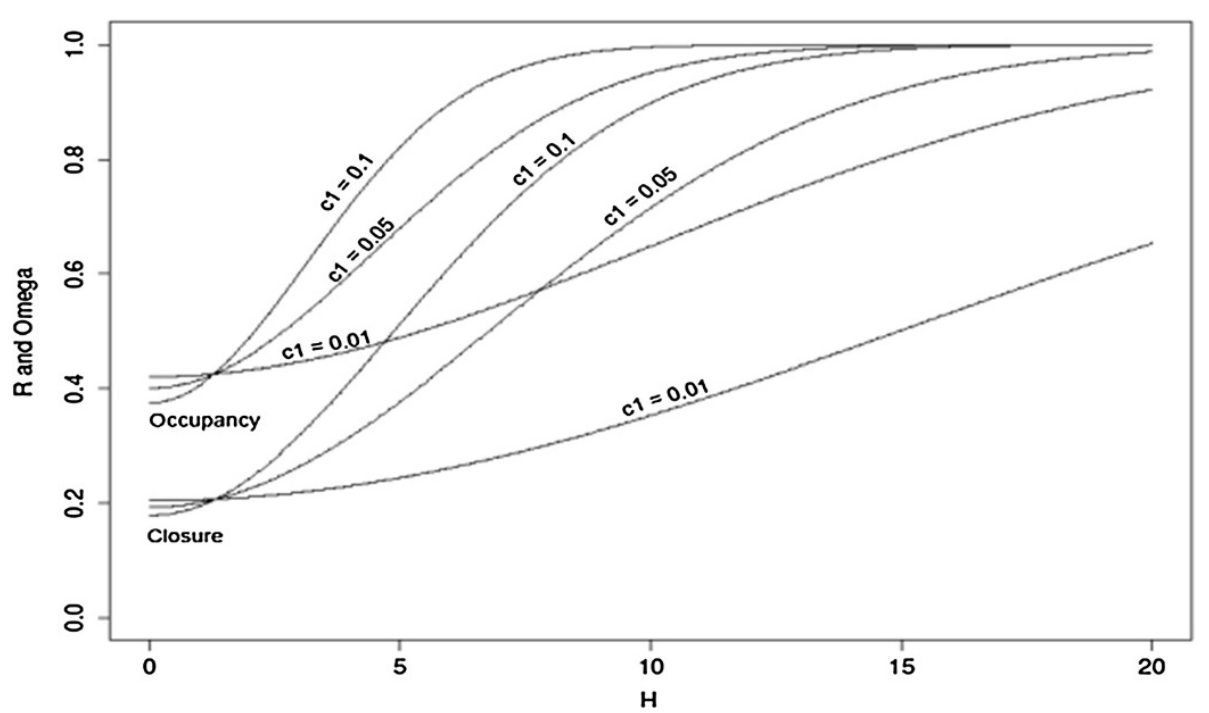

Figure 3 Closure and occupancy curves.

and 9 years, respectively (Castedo-Dorado et al., 2007). However, the models used for Scots pine and radiata pine in Galicia included projection intervals longer than those used in this study. Considering the required accuracy in forest growth modelling, where a mean prediction error of $\pm 10-20 \%$ is generally acceptable (Huang et al., 2003), it may be stated that the dynamic model provides satisfactory estimates within the range of ages and the projection intervals observed.

A plot of observed against predicted values of total stand volume, estimated using the whole dynamic stand growth model, is shown in Figure 4. The linear model fitted to the scatter plot behaved well $\left(R^{2}=0.9743\right)$, although there appears to be a slight tendency towards underestimation for low volumes and overestimation for high volumes.

Table 4 Parameter estimates for the transition functions in mortality and in basal area (Equations 4 and 12, respectively) obtained by fitting the models simultaneously

\begin{tabular}{|c|c|c|c|c|}
\hline Model & Parameter & Estimate & RMSE & $\begin{array}{c}\text { Adjusted model } \\
\text { efficiency }\end{array}$ \\
\hline \multirow{4}{*}{$\begin{array}{l}\text { Equation (4) } \\
\frac{a_{2}+1}{1-a_{3}}=2^{*}\end{array}$} & $a_{1}$ & $1.67 \times 10^{-8}$ & \multirow[t]{4}{*}{38.3550} & \multirow[t]{4}{*}{0.9877} \\
\hline & $a_{2}$ & 1.8703 & & \\
\hline & $a_{3}$ & 2.4352 & & \\
\hline & rho & 0.0684 & & \\
\hline \multirow[t]{4}{*}{ Equation (12) } & $k$ & $0.4^{*}$ & \multirow[t]{4}{*}{0.5731} & \multirow[t]{4}{*}{0.9937} \\
\hline & $c_{1}$ & $0.1^{*}$ & & \\
\hline & $b_{1}$ & 0.1663 & & \\
\hline & rho & 0.0504 & & \\
\hline
\end{tabular}

The goodness-of-fit-statistics were calculated without considering the initialized point at breast height.

*indicated the parameter value was fixed in the model, therefore, it was not estimated.

\section{Conclusions}

Forest management planning relies heavily on mathematical models that involve time. Modern dynamical system theory provides a framework for a flexible representation of varying environments, as well as of responses to intensive silviculture and natural disturbances.

A biologically consistent whole-stand growth model has been presented for teak stands in Karnataka State of India. The transition functions for mortality and basal area were fitted simultaneously, using the full information maximum likelihood, which produced consistent and efficient estimates contributing to increased precision of model predictions. Also, autoregressive procedure was

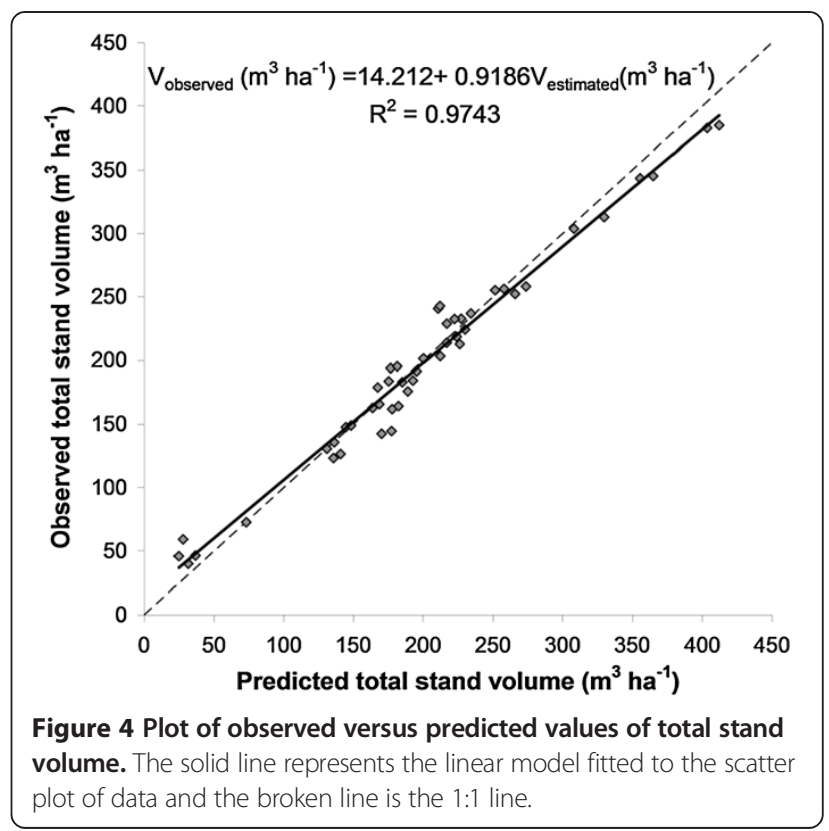


used to avoid the problem of autocorrelation inherent in the dataset from repeated measurements. The dynamic model presented provides satisfactory estimates within the range of ages and the projection intervals observed. The total volume equation was fitted generalized method of moments which produced efficient parameter estimates under heteroscedastic conditions even without estimating the heteroscedastic error variance. There was a slight tendency towards underestimation for low volumes and overestimation for high volumes.

A simple dynamical model for even-aged stands was used which performed very well. Confidence in extrapolations outside the scope of the observations is improved by following generally accepted biological principles. Application of similar models to other species and localities seems promising, in particular for data-poor situations where a small number of free parameters are desirable (Murray and von Gadow, 1993; Vanclay, 2010).

The presentation in this paper is a good demonstration of developing a dynamic growth model with limited data. There are some deficiencies in the use of the data and choice of models and methods that could be improved. In the future, more extensive data, both from unthinned and thinned stands covering wider range of ages, densities and site qualities, would allow a more robust model to be developed, that could be extended to model the effects of climate and nutrition, and biomass and carbon outputs.

\section{Appendix}

Solution of the differential equation (9)

$$
\frac{d W}{d H}=b_{1} \Omega H N^{k}+k W \frac{d \log N}{d H}=b_{1} \Omega H N^{k}+k \frac{W}{N} \frac{d N}{d H}
$$

Solving equation (11) by $\Omega$ and substituting in equation (a) gives the relationship:

$$
\frac{d W}{d H}=b_{1} H N^{k}\left[1-\exp \left(-c_{1} H^{2} / 2\right)\right]+k \frac{W}{N} \frac{d N}{d H}
$$

Integrating equation (2) the following relationship is obtained:

$$
\frac{d N}{N^{a_{3}}}=-a_{1} H^{a_{2}} d H \Rightarrow N=\left[\frac{a_{1}\left(a_{3}-1\right)}{a_{2}+1} H^{a_{2}+1}\right]^{\frac{1}{1-a_{3}}}
$$

Substituting this relationship in equation (2) and multiplying in both sides by $1 / \mathrm{N}$ :

$$
\begin{aligned}
\frac{1}{N} \frac{d N}{d H} & =-a_{1} H^{a_{2}} N^{a_{3}-1}=-a_{1} H^{a_{2}}\left[\frac{a_{1}\left(a_{3}-1\right)}{a_{2}+1} H^{a_{2}+1}\right]^{\frac{a_{3}-1}{1-a_{3}}} \\
& =-\frac{a_{2}+1}{\left(a_{3}-1\right) H}
\end{aligned}
$$

Substituting equations (c) and (d) in equation (b):

$$
\begin{aligned}
& \begin{aligned}
\frac{d W}{d H} & =\beta H^{\alpha+1}\left[1-\exp \left(-c_{1} H^{2} / 2\right)\right]+\alpha \frac{W}{H} \Rightarrow \frac{d W}{d H}-\alpha \frac{W}{H} \\
& =\beta H^{\alpha+1}\left[1-\exp \left(-c_{1} H^{2} / 2\right)\right]
\end{aligned} \\
& \text { with } \alpha=-\frac{k\left(a_{2}+1\right)}{a_{3}-1} \text { and } \beta=b_{1}\left[\frac{a_{1}\left(a_{3}-1\right)}{a_{2}+1}\right]^{\frac{k}{1-a_{3}}}
\end{aligned}
$$

Multiplying equation (e) by $H^{-\alpha}$ :

$$
\frac{d W}{d H} H^{-\alpha}-\alpha \frac{W}{H} H^{-\alpha}=\beta H\left[1-\exp \left(-c_{1} H^{2} / 2\right)\right]
$$

Integrating both sides of equation (f) respect to $d H$ :

$$
\begin{aligned}
W H^{-\alpha} & =\beta\left[\int H d H-\int H \exp \left(-c_{1} H^{2} / 2\right) d H\right] \Rightarrow \frac{W H^{-\alpha}}{\beta} \\
& =\left[\frac{H^{2}}{2}+\frac{1}{c_{1}} \exp \left(-c_{1} H^{2} / 2\right)+c t e\right]
\end{aligned}
$$

Substituting $\alpha$ and $\beta$ in the left side and $\Omega$ in the right side of equation $(\mathrm{g})$ the following invariant is obtained:

$$
\begin{aligned}
\frac{W H^{-\alpha}}{\beta} & =W \frac{1}{b_{1}\left[\frac{a_{1}\left(a_{3}-1\right)}{a_{2}+1} H^{a_{2}+1}\right]^{\frac{k}{1-a_{3}}}} \\
& =\frac{W N^{-k}}{b_{1}} \Rightarrow W N^{-k}-b_{1}\left(\frac{H^{2}}{2}-\frac{\Omega}{c_{1}}\right)=\mathrm{constant}
\end{aligned}
$$

And taking into account that $W=B H$, the transition function for basal area (Equation 12) is obtained:

$$
B_{2}=N_{2}^{k}\left(B_{1} H_{1} N_{1}^{-k}+b_{1}\left[\left(H_{2}^{2}-H_{1}^{2}\right) / 2-\left(\Omega_{2}-\Omega_{1}\right) / c_{1}\right]\right) / H_{2}
$$

\section{Competing interests}

The authors declare that they have no competing interests.

\section{Authors' contribution}

Authors' contributions: AB carried out the field work, data collection and preparation of them. JGA did the data analysis and updation of the article. OG suggested the state-approach models, helped in data analysis and edited the final version of the ms. All authors read and approved the final

manuscript.

\section{Acknowledgements}

The authors thank the Director, IWST for providing all the necessary facilities to carry out this study. The contribution of Sh. N. Chandrashekar, RA-I and Sh. H. Sangamesh, JRF in field data collection is highly appreciated. The authors are also thankful to the officials of Karnataka State Forest Department 
for granting permission to conduct the study in their teak stands and also for extending help and support during the field work.

\section{Author details}

${ }^{1}$ Forest Biometry Division, Institute of Wood Science and Technology, Bangalore, India. ${ }^{2}$ Unidad de Gestión Forestal Sostenible, Departamento de Ingeniería Agroforestal, Universidad de Santiago de Compostela, Lugo, Spain. ${ }^{3}$ University of Northern British Columbia, Columbia, BC, Canada.

\section{Received: 25 October 2013 Accepted: 17 January 2014}

Published: 2 May 2014

\section{References}

Bailey RL, Clutter JL (1974) Base-age invariant polymorphic site curves. For Sci 20:155-159

Ball JB, Pandey D, Hirai S (2000) Proceedings of the Regional Seminar on Site, Technology and Productivity of teak plantations. Global overview of teak plantations, Chiang Mai, Thailand, pp 11-34, 26-29 January 1999

Bhat KM, Ma Hwan O (2004) Teak growers unite. ITTO Trop Forest Update 14(1):3-5

Burkhart HE (2008) Modelling growth and yield for intensively managed forests. J For Sci 24(3):119-124

Castedo-Dorado F, Diéguez-Aranda U, Álvarez-González JG (2007) A growth model for Pinus radiata D. Don stands in north-western Spain. Ann For Sci 64:453-465

Chakrbarti SK, Gaharwar KS (1995) A study on volume equation for Indian teak. Indian Forester 121(6):503-509

Cieszewski CJ (2002) Comparing fixed-and variable-base-age site equations having single versus multiple asymptotes. For Sci 48(1):7-23

Cieszewski CJ, Bailey RL (2000) Generalized algebraic difference approach: theory based derivation of dynamic site equations with polymorphism and variable asymptotes. For Sci 46:116-126

Diéguez-Aranda U, Castedo F, Álvarez JG, Rojo A (2006) Dynamic growth model for scots pine (Pinus sylvestris L.) plantations in Galicia (north-western Spain). Ecol Model 191:225-242

Eid T, Tuhus E (2001) Models for individual tree mortality in Norway. For Ecol Manag 154:69-84

García O (1994) The state-space approach in growth modelling. Can J For Res 24:1894-1903

García O (2009) A simple and effective forest stand mortality model. Int J Mathemat Comp Forest Nat-Res Sci (MCFNS) 1(1):1-9

García O (2011) A parsimonious dynamic stand model for interior spruce in British Columbia. For Sci 57(4):265-280

García O (2013) Building a dynamic growth model for trembling aspen in western Canada without age data. Can J For Res 43(3):256-265

García O, Burkhart HE, Amateis RL (2011) A biologically-consistent stand growth model for loblolly pine in the piedmont physiographic region, USA. For Ecol Manag 262(11):2035-2041

Goldberger AS (1964) Econometric Theory. John Wiley and Sons, New York, p 399

Greene WH (2012) Econometric Analysis, 7th edn. Prentice Hall, Upper Saddle River, p 1232

Horne JEM (1966) Teak in Nigeria. Nigerian Info Bull (New Series) 16:40

Huang S, Yang Y, Wang Y (2003) A Critical Look at Procedures for Validating Growth and Yield Models. In: Amaro A, Reed D, Soares P (eds) Modelling Forest Systems. CAB International, Wallingford, Oxfordshire, UK, pp 271-293

Husch B, Beers TW, Kershaw JA (2003) Forest Mensuration, 4th edn. John Wiley and Sons, New York, p 443

Judge GG, Hill RC, Griffiths WE, Lütkepohl H, Lee TC (1988) Introduction to the Theory and Practice of Econometrics, 2nd edn. John Wiley and Sons, New York, p 1064

Kadambi K (1972) Silviculture and Management of Teak. Bulletin 24, School of Forestry, Stephen F. Austin State University, Texas, p 25

Mohren GMJ, Burkhart HE (1994) Contrasts between biologically-based process models and management-oriented growth and yield models. For Ecol Manag 69:1-5

Monserud RA, Sterba H (1999) Modeling individual tree mortality for Austrian forest species. For Ecol Manag 113:109-123

Murray DM, Gadow KV (1993) A flexible yield model for regional timber forecasting. South J Appl For 17:112-115

Pandey D (1998) Forest Plantation Areas, 1995. FAO, Rome. Report of the FAO Project GCP/INT/628/UK. p 94
Parresol BR (2001) Additivity of nonlinear biomass equations. Can J For Res $31: 865-878$

Pérez LD, Kanninen M (2003) Heartwood, Sapwood and bark content, and wood dry density of young and mature teak (Tectona grandis) trees grown in Costa Rica. Silva Fennica 37(1):45-54

Reynolds MR Jr (1984) Estimating the error in model predictions. For Sc 30:454-469

SAS Institute Inc (2008) SAS/ETS ${ }^{\circledR} 9.2$ User's Guide. SAS Institute Inc, Cary, NC

Tewari VP, Mariswamy KM, Arunkumar AN (2013) Total and merchantable volume equations for Tectona grandis linn f. Plantations in Karnataka, India. Justain For 32(3):213-229

Tewari VP, Álvarez-González JG, Gadow KV (2014) Dynamic Base-age Invariant Site Index Models for Tectona Grandis in Peninsular India. Southern Forests, 76(1):21-27 http://dx.doi.org/10.2989/20702620.2013.870398

Troup RS (1921) The Silviculture of Indian Trees, Vol. Ilth edn. Clarendon, Oxford Van Laar A, Akça A (2007) Forest Mensuration, 2nd edn. Springer, New York, p 383 Vanclay JK (2010) Robust relationships for simple plantation growth models based on sparse data. For Ecol Manag 259(5):1050-1054

Weiskittel AR, Hann DW, Kershaw JA, Vanclay J (2011) Forest Growth and Yield Modelling. Wiley-Blackwell, Oxford, p 415

White KJ (1991) Teak-Some Aspects of Research and Development. Publication 1991/17. FAO, Bangkok, p 44

doi:10.1186/2197-5620-1-9

Cite this article as: Tewari et al:: Developing a dynamic growth model

for teak plantations in India. Forest Ecosystems 2014 1:9.

\section{Submit your manuscript to a SpringerOpen ${ }^{\odot}$ journal and benefit from:}

- Convenient online submission

- Rigorous peer review

- Immediate publication on acceptance

- Open access: articles freely available online

- High visibility within the field

- Retaining the copyright to your article

Submit your next manuscript at $>$ springeropen.com 